\title{
EFFECT OF THE CELLULAR CONSTITUENTS OF THE NITROGEN-FIXING BLUE-GREEN ALGA, CYLINDROSPERMUM MUSCICOLA, ON THE ROOT GROWTH OF RICE PLANTS
}

\author{
G. S. VENKATARAMAN AND S. NEELAKANTAN \\ Division of Microbiology, Indian Agricultural Research Institute, \\ New Delhi, India
}

(Received February 6, 1967)

\begin{abstract}
The present observation indicates that, besides the nitrogenous compounds, other biologically active cell constituents like vitamin $\mathrm{B}_{12}$ and auxins may also appreciably contribute to the fertilizing action of the nitrogen-fixing blue-green algae. Of the various intracellular amino acids of Cylindrospermum muscicola, cystine, tyrosine and phenylalanine seem to be available to the rice plants. The alga can synthesize vitamin $B_{12}$ active compounds, the yield of which was about 1.2 to $1.5 \mu \mathrm{g} / \mathrm{g}$ dry weight of the alga. The synthesis of these compounds was promoted by the addition of cobalt salt. The alga also contains interconvertible auxin-like substances which stimulate the root growth of rice seedlings.
\end{abstract}

The fertilizing action of the nitrogen-fixing blue-green algae has been generally attributed to the release of the nitrogenous compounds synthesized by them, either by excretion or decomposition of the algal cells. It is also likely that cell constituents of these organisms, other than the nitrogenous ones, may also play an important role in stimulating the crop growth (1). The present investigation was undertaken to obtain fundamental information on the nature of the cellular constituents, including the nitrogenous ones, of the blue-green alga, Cylindrospermum muscicola, which may contribute to the fertilizing action of the alga.

\section{MATERIALS AND METHODS}

Cultivation of the alga: The nitrogen-fixing blue-green alga, Cylindrospermum muscicola, was isolated from the paddy field soils of Rajasthan

IAA: 3-indoleacetic acid;

IPA: 3-indolepropionic acid;

EDTA: ethylenediaminetetraacetic acid;
IAN: 3-indoleacetonitrile;

TFA: trifluoroacetic acid;

EtOH: ethyl alcohol 
State, by methods described earlier $(2,3)$. The alga was grown at $30-32^{\circ}$ under illumination with 40 watt fluorescent lamps ( $c a$ 5,000 lux) in a medium which contained per liter of distilled water: $0.2 \mathrm{~g} \mathrm{~K} \mathrm{HPO}_{4}, 0.2 \mathrm{~g} \mathrm{MgSO}_{4} \cdot 7 \mathrm{H}_{2} \mathrm{O}$, $0.1 \mathrm{~g} \mathrm{CaCl}_{2}, 0.5 \mathrm{ml}$ Fe-EDTA and $1 \mathrm{ml}$ Arnon's $\mathrm{A}_{5}$ micronutrient solution. After three weeks of growth, the alga was collected by centrifugation, aseptically washed and used for the experiments.

Separation of amino acids: For the cellular amino acids, the alga was hydrolysed with $6 \mathrm{~N}$ hydrochloric acid and the hydrolysate was subjected to unidimensional ascending paper chromatography, using $n$-butanol: acetic acid: water $(4: 1: 1)$ as the solvent. The developed chromatogram was cut into 10 equal pieces, each piece eluted and used for studying their effect on the growth of rice seedlings. The amino acids in the cut regions were identified by two dimensional paper chromatography using water-saturated phenol as the first developing solvent and butanol-acetic acid-water as the second solvent. The effect of the intracellular amino acids in the algal body on the root growth was also compared with standard amino acids (BDH or E. Merck) for confirmation.

Separation of bases: Hydrolysis of the nucleic acid fractions was carried out with TFA at $150^{\circ}$ for $80 \mathrm{~min}$ and the hydrolysate was chromatographed using iso-propanol: hydrochloric acid: water (34:8:8) (4). The base regions were cut, eluted and used for growth tests wtih paddy seedlings. They were compared with standard bases also.

Extraction and bio-assay of auxin-like substances: The alga was frozen, thawed, acidified to $\mathrm{pH} 5$ and extracted with ether. The dried ether extract was partitioned between $95 \%$ methanol and petroleum ether and the petrol fraction rejected. The methanol fraction was separated into acidic and neutral components. The Avena straight growth method was used for assaying the auxins (5). The extract was purified by preliminary chromatography using water as eluent. The pigment remaining at the starting point was rejected and the remainder of the chromatogram was floated in $\mathrm{EtOH}$ and the recovered material rechromatographed in iso-propanol:ammonia:water $(10: 1: 1)$. The chromatogram was cut into ten equal pieces, eluted and tested for its activity with Avena coleoptiles. The complete chromatogram was also used for colour tests with Ehrlich and nitrous-nitric acid reagents.

Extraction and assay of vitamin $B_{12}$ active compounds. To $10 \mathrm{mg}$ algal material were added $5 \mathrm{ml}$ distilled water and 1 to 5 drops of acetate buffer $(\mathrm{pH} 4.5)$ and boiled. The $\mathrm{pH}$ of the extract was adjusted to 6 with sodium hydroxide, filtered and the volume was made up to $5 \mathrm{ml}$ with distilled water. One liter of the buffer contained $207 \mathrm{~g}$ sodium acetate and $126 \mathrm{~g}$ acetic acid (6). A parallel extraction was also made with boiling water alone to compare with buffer extraction.

The assay of the vitamin $\mathrm{B}_{12}$ active compounds was done with Escherichia coli 113-3, the basal medium for which contained per liter of distilled water: $7.0 \mathrm{~g} \mathrm{~K}_{2} \mathrm{HPO}_{4}, 0.5 \mathrm{~g}$ Na-citrate $\cdot 3 \mathrm{H}_{2} \mathrm{O}, 0.1 \mathrm{~g} \mathrm{MgSO}_{4} \cdot 7 \mathrm{H}_{2} \mathrm{O}, 1.0 \mathrm{~g}\left(\mathrm{NH}_{4}\right)_{2} \mathrm{SO}_{4}$ and 
$2 \mathrm{~g}$ glucose $(\mathrm{pH} 6.8)(6)$ Incubation period, temperature and wavelength for turbidity measurements were $22 \mathrm{hrs}, 37^{\circ}$ and $560 \mathrm{~m} \mu$, respectively.

Growth tests with rice seedling: Seed lots of paddy variety Zona 359 were used. The germination capacity was not less than $95 \%$ under optimum conditions of standard germination tests. For each test, 20 replications, each containing ten surface sterilized seeds were used (total 200 seeds for each test). The seeds were allowed to germinate in sterile petri dishes padded with sterile filter paper. Five milliliters of RICHARD's medium (7) (without sugar) were added to each petri dish and fortified with different eluted and standard substances. After 3 days germination, the root lengths were measured in each treatment to the nearest millimeter. The data were statistically analysed by the Random Block method.

\section{RESULTS}

Effect of intracellular algal amino acids on the growth of rice roots.

Fig. 1 shows that three regions in the algal hydrolysate brought about a significant stimulation of root growth, the concerned regions corresponding

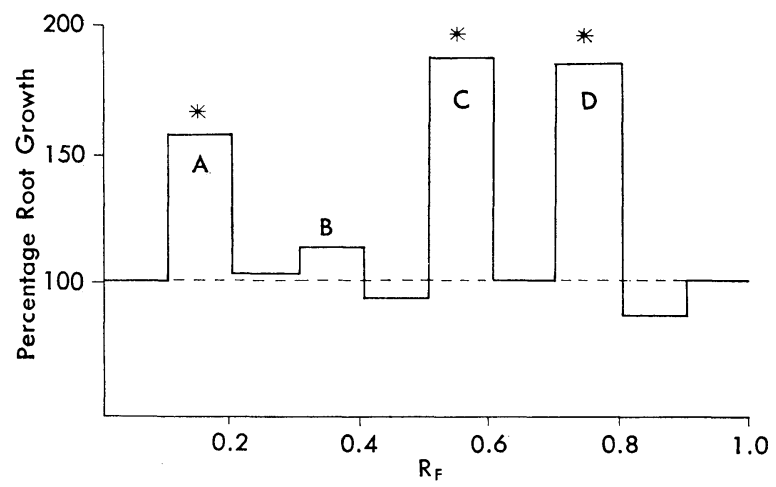

Fig. 1. Root growth in 3-day old rice seedlings treated with different regions of the chromatogram of the acid hydrolysate of Cylindrospermum muscicola (solvent: $n$-butanol:acetic acid:water).

A, cystine, lysine; $\mathrm{B}$, serine, glycine; $\mathrm{C}$, alanine, proline, tyrosine; D, tryptophan, valine, phenylalanine.

to (A) cystine, lysine, (C) alanine, proline and tyrosine and (D) tryptophan, valine and phenylalanine. The slight stimulation in the region (B) containing serine and glycine was not statistically significant. When the effect of the algal amino acids were compared with standard amino acids to find out which of them was responsible for the stimulatory effect, it was observed that only cystine, tyrosine and phenylalanine significantly stimulated the root growth (Fig. 2). This suggests that these three amino acids present in the 


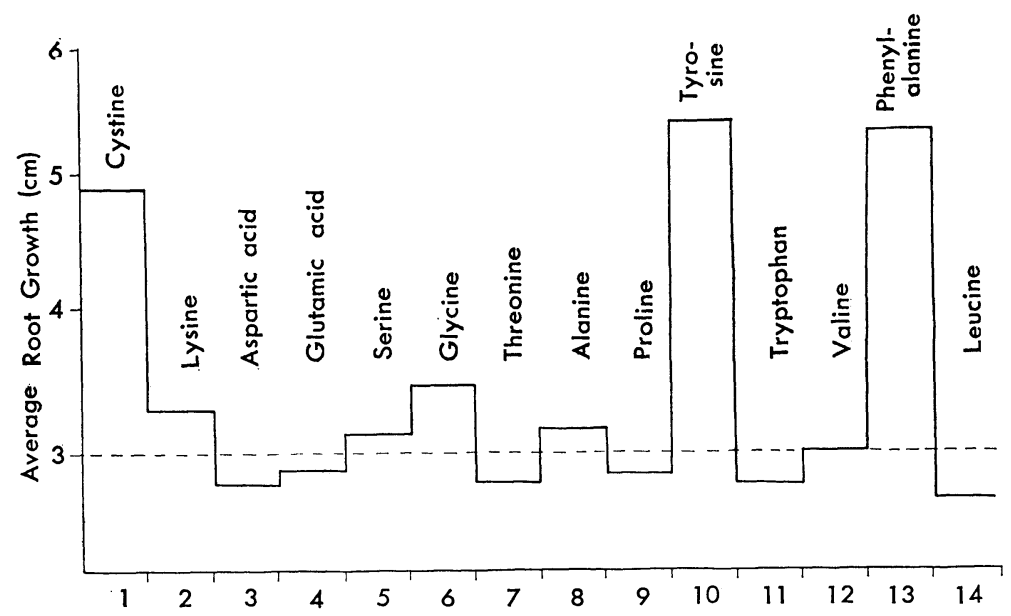

Fig. 2. Root growth in 3-day old rice seedlings treated with standard amino acids (Final concentration $0.1 \mu \mathrm{g}$ ) (Significant at $1 \%$ level; $\mathrm{S}_{e}=0.14$; C. D. at $1 \%$ level 0.52 )

algal body are available to the rice plants and promote the root growth of the crop.

Effect of base fractions on the root growth of rice seedlings.

None of the base fractions in the algal body had any stimulating effect on the growth of rice roots. So was the case with standard bases also.

Vitamin $B_{12}$ active compounds in the alga.

Table 1 shows the level of vitamin $B_{12}$ activity in the alga under two conditions of extraction, which shows that acetate buffer extraction is as good as boiling water extraction $(6)$.

The synthesis of these active compounds under different nutritive conditions by the alga was also examined, using different media (6) (Table 2).

From Table 2, it is seen that the production of vitamin $B_{12}$ active compounds by the alga was promoted by the addition of cobalt salt and not much affected by the addition of nitrogen or carbon sources. When the extract of

Table 1. Activity of vitamin $B_{12}$ active compounds in Cylindrospermum muscicola $(\mu \mathrm{g} / \mathrm{g}$ dry wt).

\begin{tabular}{c|c}
\hline Acetate buffer extraction & Boiling water extraction \\
\hline 1.23 & 1.52 \\
1.50 & 1.71 \\
1.12 & 1.39 \\
Average $(1.28)$ & $(1.54)$ \\
\hline
\end{tabular}


Table 2. Vitamin $\mathrm{B}_{12}$ activity in Cylindrospermum muscicola under different nutrient conditions.

\begin{tabular}{ll|c}
\hline \multicolumn{1}{c|}{ Treatments } & Vitamin $\mathrm{B}_{12}$ activity $(\mu \mathrm{g} / \mathrm{g})$ \\
\hline 1. & Basal medium & 1.26 \\
2. & Cobalt added $\left(0.2 \mathrm{mg} \mathrm{CoCl}_{2} \cdot 6 \mathrm{H}_{2} \mathrm{O} / 1\right)$ & 2.93 \\
3. & Nitrogen source added $\left(0.5 \mathrm{~g} \mathrm{NH}_{4} \mathrm{NO}_{3} / 1\right)$ & 1.70 \\
4. & $(2)+(3)$ & 2.22 \\
5. & Carbon source added $(2 \mathrm{~g}$ glucose $/ 1)$ & 1.30 \\
6. & $(2)+(5)$ & 2.62 \\
7. & $(3)+(5)$ & 1.43 \\
8. & $(2)+(3)+(5)$ & 2.45 \\
\hline
\end{tabular}

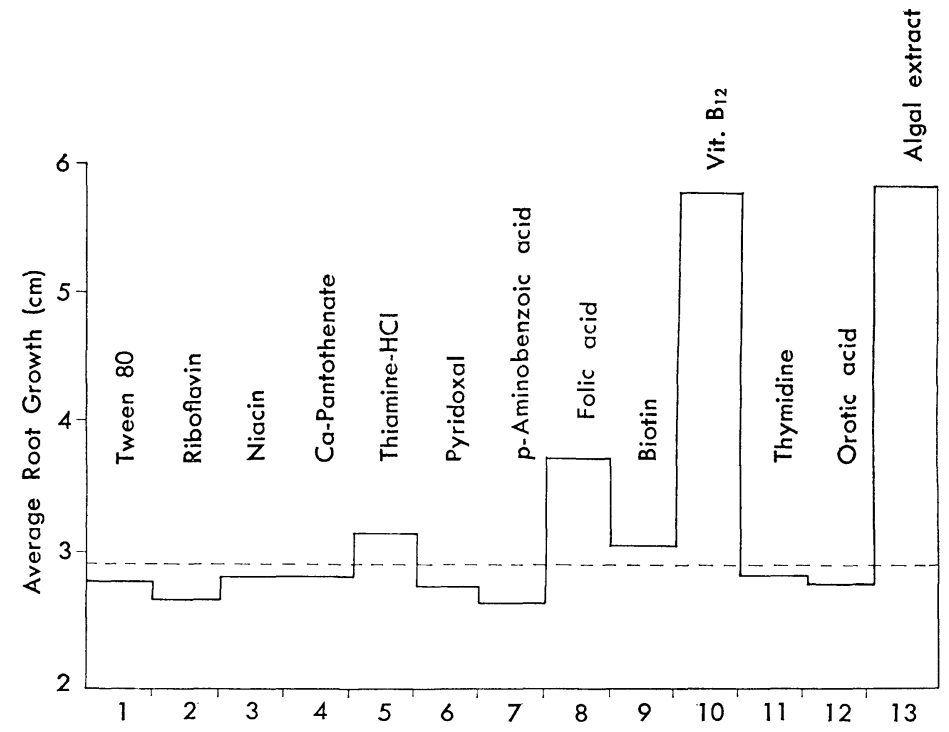

Fig. 3. Root growth in 3-day old rice seedlings treated with standard growth factors and acetate buffer algal extract (Final concentration $0.25 \mu \mathrm{g}$ ) (Significant at 1\% level; $\mathrm{S}_{e}=0.135 ;$ C. D. at $1 \%$ level 0.5 ).

vitamin $\mathrm{B}_{12}$ active compounds from the alga was tested on the root growth and compared with the effects of twelve known growth factors, it was observed that the effect of the algal extract was comparable to that of pure vitamin $\mathrm{B}_{12}$ (Fig. 3). Slight growth stimulation was also observed with standard folic acid and thiamine, but they were not of the magnitude of that of vitamin $\mathrm{B}_{12}$. The presence of 1.2 to $1.5 \mu \mathrm{g}$ of vitamin active compounds in the algal body and its stimulating effect on the root growth suggest that this alga provides this important biologically active substance to the rice plants, besides 
the nitrogenous compounds like amino acids.

Presence of auxin-like substances in the algal body.

Hormone profiles of the alga showed two clear zones of activity, ' $X$ ' and ' $\mathrm{Z}$ ' (Fig. $4 \mathrm{~A}$ ). When the ' $\mathrm{X}$ ' zone was eluted and rechromatographed in $n$-butanol:EtOH: $1.5 \mathrm{~N}$ ammonia $(6: 2: 2)$, zone ' $\mathrm{Z}$ ' appeared in addition to

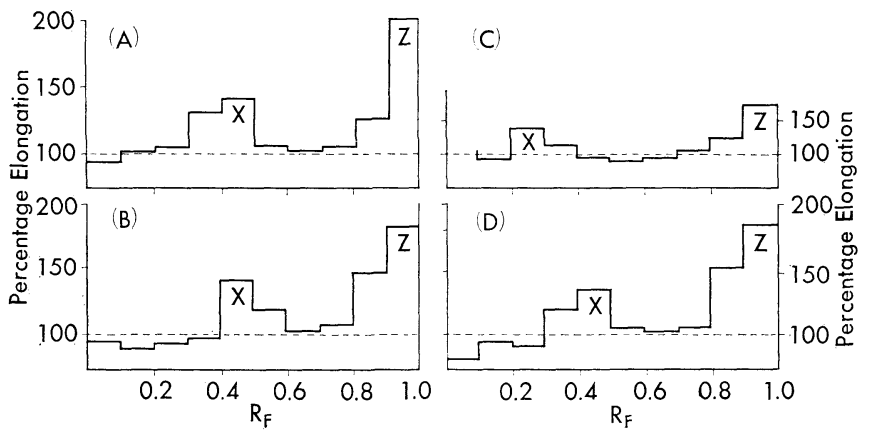

Fig. 4. Auxin activity in the algal body. A, acidic ether fraction chromatographed in iso-propanol-ammonia-water (10:1:1); $\mathrm{B}$, zone $\mathrm{RF}_{\mathrm{F}} 0.3$ to 0.5 of (A) eluted and rechromatographed in $n$ butanol: EtOH: $1.5 \mathrm{~N}$ ammonia $(6: 2: 2)$; $\mathrm{C}$, zone $\mathrm{RF}_{\mathrm{F}} 0.3$ to 0.5 of $(\mathrm{A})$ autoclaved with $\mathrm{N} \mathrm{HCl}$, extracted with ether and rechromatographed in ammoniacal iso-propanol; $\mathrm{D}$, zone $\mathrm{RF}_{\mathrm{F}} 0.8$ to 1.0 of (A) eluted and rechromatographed in ammoniacal iso-propanol.

Table 3. Effect of IAA, IPA and tryptophan on the root growth of rice seedlings.

\begin{tabular}{l|c}
\hline \multicolumn{1}{c}{ Final concentration } & Root length $(\mathrm{cm})$ \\
\hline Control & 2.82 \\
IAA $(0.001 \mu \mathrm{g})$ & 2.87 \\
IPA $(0.001 \mu \mathrm{g})$ & 5.64 \\
Tryptophan $(0.1 \mu \mathrm{g})$ & 2.82 \\
\hline
\end{tabular}

zone ' $\mathrm{X}$ ' (Fig. 4B). Similarly, when ' $\mathrm{Z}$ ' zone was eluted and rechromatographed in iso-propanol:ammonia: water, zone ' $\mathrm{X}$ ' appeared (Fig. 4D). Thus, there seems to be a mutual interconvertibility between these two zones as seen in a number of other algae $(8,9)$, tomato roots $(10)$ and pea roots $(11)$. The two zones of activity, ' $\mathrm{X}$ ' and ' $\mathrm{Z}$ ', on the chromatogram correspond to the positions of IAA and IAN respectively. However, zone ' $X$ ' survived autoclaving with $1 \mathrm{~N} \mathrm{HCl}$ (Fig. 4C). Besides, IAA does not give activity in zone ' $\mathrm{Z}$ ' on rechromatography as zone ' $\mathrm{X}$ ' did. This, however, does not rule out the possibility of the presence of IAA in addition to some other compounds. Pure IAA or tryptophan, the precursor of IAA, had no effect on the root 
growth, whereas IPA had a pronounced stimulating effect (Table 3). Zone ' $\mathrm{Z}$ ' gave a pink nitrous acid reaction and a pink or purple Ehrlich reaction, whereas IAN is known to give a brownish purple reaction with the former and a greenish blue with the latter.

Table 4 shows the effect of ' $\mathrm{X}$ ' and ' $\mathrm{Z}$ ' zones on the root growth, from which it appears that these auxin regions significantly stimulated the root growth.

Table 4, Effect of ' $\mathrm{X}$ ' and ' $\mathrm{Z}$ ' zones on the root growth of rice seedlings.

\begin{tabular}{|c|c|c|}
\hline & & $\%$ increase over control \\
\hline \multirow[t]{3}{*}{ a) } & Acid ether fraction chromatographed & \\
\hline & ' $\mathrm{X}$ ' zone & 160 \\
\hline & ' Z' zone & 210 \\
\hline \multirow[t]{3}{*}{ b) } & ' $\mathrm{X}$ ' zone eluted \& rechromatographed & \\
\hline & ' $\mathrm{X}$ ' zone & 155 \\
\hline & ' Z' zone & 202 \\
\hline \multirow[t]{3}{*}{ c) } & ' $\mathrm{Z}$ ' zone eluted \& rechromatographed & \\
\hline & ' $\mathrm{X}$ ' zone & 162 \\
\hline & ' $\mathrm{Z}$ ' zone & 180 \\
\hline
\end{tabular}

The occurrence of auxin-like substances in the algal body and their stimulatory effect on the root growth suggest that these substances may also contribute to the fertilizing action of the alga.

\section{DISCUSSION}

The present investigation shows that, besides the nitrogenous compounds, the algal body contains many biologically active compounds like vitamin $\mathrm{B}_{12}$ and auxin-like substances, which may considerably add to the fertilizing action of the alga. Of the various cellular amino acids, only cystine, tyrosine and phenylalanine seemed to stimulate the growth of paddy roots significantly. The base fractions, on the other hand, had no effect.

Besides these nitrogenous compounds, the alga contained appreciable amounts of vitamin $B_{12}$ active compounds, the synthesis of which was promoted by the addition of cobalt salt but not so much by the addition of nitrogen or carbon sources $(6)$. When the vitamin extract from the algal body was compared with pure vitamin $\mathrm{B}_{12}$, it was observed that their effects in stimulating the root growth of rice seedlings were comparable and significantly higher than those of eleven other known growth factors (Fig. 3). Vitamin $\mathrm{B}_{12}$ was earlier believed to be produced by some bacteria, actinomycetes, fungi and yeasts, until these substances were detected in a 
number of algae $(6,12,13,14,15,16)$. The presence of this substance in the nitrogen-fixing alga is particularly significant when the crop-alga association is considered.

The presence of auxin-like substances in the algal body will also have an important role in the crop growth. The two zones of activity, ' $X$ ' and ' $\mathrm{Z}$ ', were found to stimulate the root growth significantly (Table 4).

Increase in root growth was also observed in thirty day old seedlings of

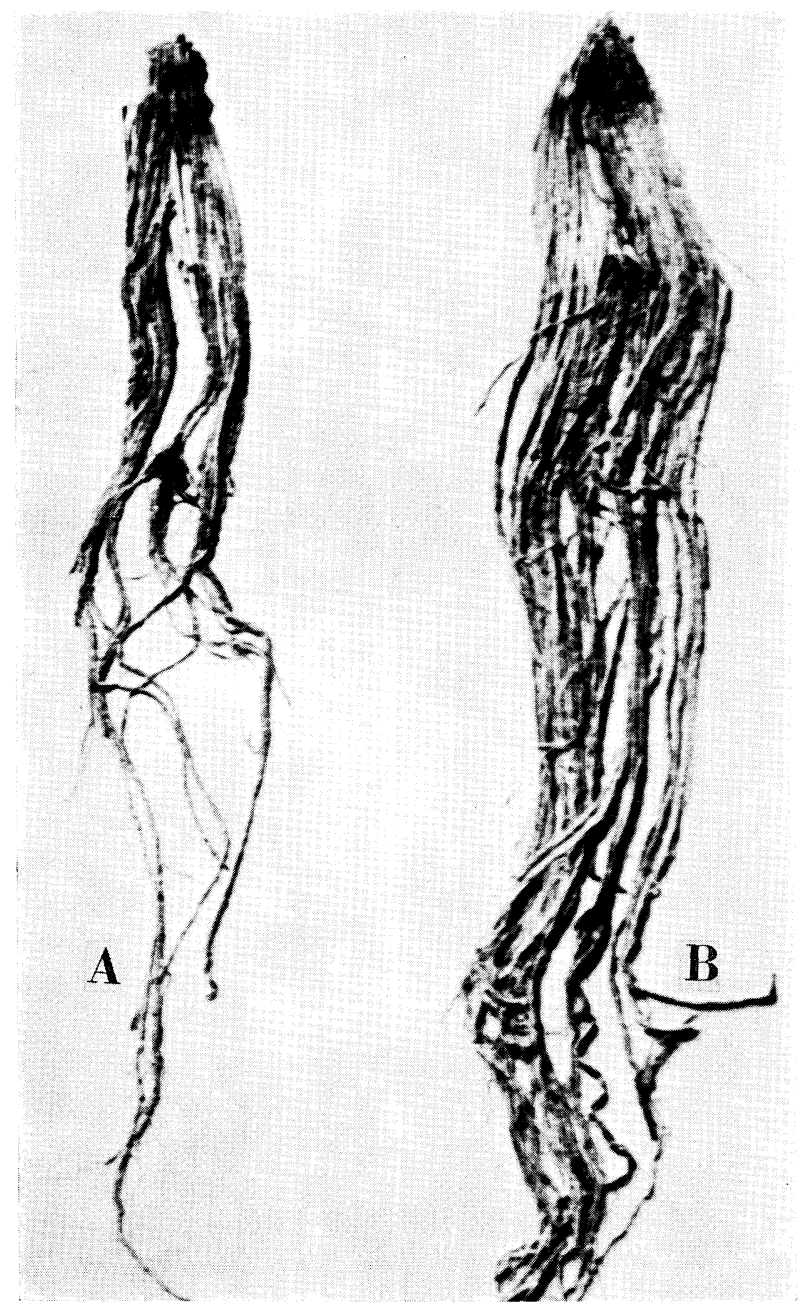

Fig. 5. Root growth in 30 day old rice plants in untreated soils (A) and in soils inoculated with the alga (B). 
rice plants under pot culture conditions, when the soil was inoculated with this alga (Table 5; Fig. 5).

Table 5. Effect of algal inoculation on the root growth of thirty day old rice plants (values average of quadruplicates).

\begin{tabular}{c|c|c}
\hline Treatments & $\begin{array}{c}\text { Dry wt. root } \\
(\mathrm{g})\end{array}$ & $\begin{array}{c}\text { \% Increase over } \\
\text { control }\end{array}$ \\
\hline Control (uninoculated) & 0.095 & - \\
Inoculated with alga & 0.18 & 89.5 \\
\hline
\end{tabular}

It thus seems that the fertilizing action of the nitrogen-fixing blue-green algae on the crop growth is due to the cumulative effect of all these biologically important factors present in the algal body. This also explains the additive effect of algal inoculation along with inorganic nitrogen fertilization in increasing the crop yield (17).

We are thankful to Dr. M. S. Swaminathan and Dr. W, V. B. Sundara Rao for their keen interest and encouragement; to Dr. V. Jagannathan, National Chemical Laboratory, Poona, for kindly supplying E. coli cultures and to Prof. Atsushi Watanabe, Seijo University, Tokyo, for valuable advice. The junior author is grateful to the Council of Scientific and Industrial Research, for the award of a fellowship to him.

\section{REFERENCES}

1) A. Watanabe and T. Kiyohara: J. Gen. Appl. Microbiol., 5, 175 (1960).

2) G. S. Venkataraman: Proc. Symp. Algology, Pub. I. C. A. R., New Delhi, p. $119(1960)$.

3) G. S. Venkataraman, N. Dutta and K. V. Natarajan: J. Indian bot. Soc., 38, 114 (1959).

4) G. R. Wyатт: Biochem. J., 48, 584 (1951).

5) J. A. Bentley and S. Housley: Physiol. Plantarum, 7, 405 (1954).

6) A. OKudA and M. YAmaguchi: Soil \& Plant Food, 6, 76 (1960).

7) T. Fahmy: Phytopathology, 13, 543 (1923).

8) J. A. Bentley: Nature, 181, 1499 (1958).

9) J. A. Bentley: J. expt. Botany, 1, 201 (1950).

10) G. Britton, S. Housley and J. A. Bentley,: J. expt. Botany, 7, 239 (1956).

11) L. J. Audus and B. E. S. Gunning: Physiol. Plantarum, 11, 685 (1958).

12) F. Brown, W. F. J. Cuthbertson and G. E. FogG: Nature, 177, 188 (1956).

13) Y. Hashimoto and A. Sato: Jap. Soc. Sci. Fish., 19, 987 (1954) (from Okuda and Yamaguchi, 1960).

14) W. J. Robbins, A. Harvey and M. E. Stebbins: Bull. Torrey bot. Club, 78, 363 (1951).

15) G. S. Venkataraman, K. M. Jacob and S. K. Goyal: Proc. natl acad. Sci., India, 34B, 153 (1964).

16) E. Henriksson: Physiol. Plantarum, 14, 813 (1956).

17) W. V. B. Sundara Ra0, S. K. Goyal and G. S. Venkataraman: Current Sci., 32, $336(1963)$. 